\title{
Modeling process intensified catalytic plate reactor for synthesis gas production
}

\author{
Prashil Lakhete, Vinod M. Janardhanan, ${ }^{1}$ \\ Department of Chemical Engineering, Indian Institute of Technology Hyderabad, Yeddumailaram, Andhra Pradesh 502 205, India
}

\begin{abstract}
This paper presents numerical study of co and counter flow arrangements for catalytic plate reactors (CPR). $\mathrm{CH}_{4}$ steam reforming coupled with $\mathrm{CH}_{4}$ oxidation is simulated using detailed surface reaction mechanisms. Effect of inlet velocities to the reforming channel, oxidation channel, and material properties of the plate on the resulting plate temperature and $\mathrm{CH}_{4}$ conversions is studied. The simulation results agree very well with an industrial scale reformer unit and calculations are further carried out to evaluate the number of CPRs and stacks required to replace and industrial unit.
\end{abstract}

Key words: Catalysis, Chemical reactors, Dynamic simulation, Energy, Numerical analysis, Autothermal

\section{Introduction}

Steam reforming (SR) of natural gas widely used for the production of synthesis gas in petrochemical and refinery units takes place in tubular reactors positioned in large gas fired furnaces. The reaction is highly endothermic and the desired reaction temperature is achieved by means of radiation from flue gas and furnace walls. Industrial scale applications generally use $\mathrm{Ni}$ as catalyst, however, $\mathrm{Rh}$ is also considered for experimental studies. As the process is bulky and has low thermal efficiency, SR at micro- and meso-scales has received increased attention over last decade (Stefanidis et al., 2009, Venkataraman, 2003, Kolb and Hessel, 2004, Stefanidis et al., 2008).

There are several advantages associated with micro-reactor technology. The small length scale makes the process safer, millimeter or sub-millimeter dimension improves heat and mass transfer and minimizes hot spot formation, and lower hold-up volume within micro-reactors reduces the magnitude of any unfortunate events like explosion or chemical release. Finally, for all processes where production rates are limited by transport, micro-reactor technology offers drastic reduction in equipment sizes leading to capital cost savings and enhanced energy efficiency.

Micro-reactors like catalytic plate reactor (CPR) for methane steam reforming reaction coupled with methane combustion reaction is discussed in this paper. There are many studies regarding steam reforming of fuel in CPR, however, most of them are simulation works barring a few.

A CPR essentially is a plate coated with a bed of catalyst material on either side with flow channel over it. A schematic

Email address: vj@iith.ac.in (Vinod M. Janardhanan) representation of CPR is shown in Fig. 1. $\mathrm{Rh}$ or $\mathrm{Ni}$ is used as reforming catalyst and $\mathrm{Pt}$ is generally used as oxidation catalyst (Stefanidis et al., 2009, Janardhanan et al., 2011). Catalyst loading, plate thickness, plate thermal conductivity, inlet velocities, and inlet temperatures are some of the operational and design parameters that affects the performance of CPR (Zanfir and Gavriilidis, 2003). CPR may be arranged in co flow or counter flow configuration. Higher conversion and better utilization of overall heat is possible with counter flow arrangement (Zanfir and Gavriilidis, 2004). However, the exit temperature can be high in counter flow configuration compared to co flow configuration and in general co flow configuration can mitigate hot spot formation (Zanfir and Gavriilidis, 2004). Since the heat requirement for reforming reaction in CPR is met by oxidation reactions occurring in a parallel channel, CPR is operated adiabatically. The presence of insulation not only increases the maximum plate temperature, but also causes steep axial temperature gradients, which may be detrimental for the catalyst and mechanical properties of the plate (Stefanidis et al., 2009). Low steam reforming velocities and high-conductivity ceramics or metals are preferred to low conductivity ceramic as plate materials as they smooth out temperature gradients.

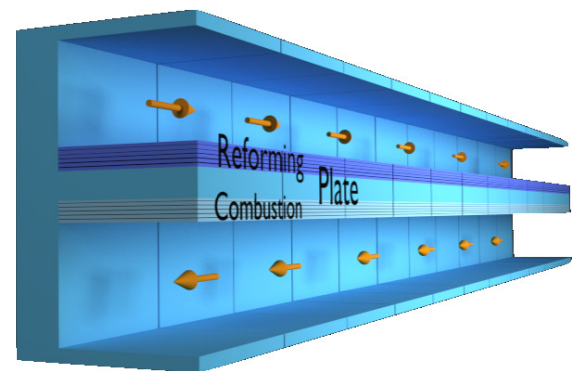

Figure 1: Schematic representation of counter flow arrangement 
Experimental reports on CPR are very scanty, particularly using $\mathrm{CH}_{4}$. Polman et al. experimentally achieved $99.98 \%$ and $97 \%$ conversions of combustion and reforming reactions, respectively, in a co-current plate reactor (Polman et al., 1999). Venkataraman et al.studied combined catalytic methane combustion on $\mathrm{Pt}$ and steam methane reforming on $\mathrm{Rh}$ in meso-scale catalytic plate reactor (Venkataraman, 2003). They reported stable operation for several hours without catalyst deactivation as well as high methane conversion (more than $95 \%$ ), with a residence time of $\sim 70 \mathrm{~ms}$ for three channel parallel plate reactor (two combustion channels and one reforming channel).

The present work deals with transient analysis of co and counter current configuration of CPR with porous catalyst applied on either side of the plate. The work differs from the above reported ones in various aspects. All the above reported work implements global reaction kinetics for reforming and oxidation, whereas in this work we implemented detailed kinetic models for the surface reactions. The porous media transport is implemented using modified Fick's Law. Counter-current arrangement of CPR is studied in detail. The model is also experimentally validated to obtain the conversions and residence time reported by Venkataraman et. al. (Venkataraman, 2003) for co-flow three channel arrangement.

\section{Numerical model}

\subsection{Channel flow}

The flow of gaseous mixture through the top and bottom channels is modeled as plug flow according to (Zhu et al., 2005).

$$
\frac{\mathrm{d}\left(\rho u Y_{k}\right)}{\mathrm{d} z}=\frac{w_{\mathrm{d}}}{A_{\mathrm{c}}} J_{k} W_{k}, \quad k=1, \ldots, K_{g}
$$

Here $w_{d}$ is width of catalyst layer and $A_{c}$ is cross sectional area of channel, $J_{k}$ is the molar flux of species $k$ at the interface between the flow channel and the porous catalyst bed. $Y_{k}$ is the mass fraction and $W_{k}$ is the molecular weight of species $k$. Since the channel dimensions we consider here are quite small $\sim 1 \mathrm{~mm}$, the plug flow assumption is adequate to represent the species transport in the channels. The velocity in the channel is calculated from

$$
\frac{\mathrm{d}(\rho u)}{\mathrm{d} z}=\sum_{k=1}^{K_{g}} \frac{w_{\mathrm{d}}}{A_{\mathrm{c}}} J_{k} W_{k}, \quad k=1, \ldots, K_{g} .
$$

The local density in the flow channel is calculated from the ideal gas equation by assuming constant pressure $p$ as

$$
\rho=\frac{p \bar{W}}{R T} .
$$

The energy balance equation for the flow channels is written as

$$
\rho u c_{\mathrm{p}} \frac{\mathrm{d} T}{\mathrm{~d} z}=\frac{4}{D_{\mathrm{h}}} h\left(T_{\mathrm{p}}-T\right)
$$

where $T_{\mathrm{p}}$ is plate temperature, $T$ is fluid temperature, $D_{\mathrm{h}}$ is hydraulic diameter of the flow channel, $c_{\mathrm{p}}$ is the specific heat capacity of the gas mixture, and $h$ is the heat transfer coefficient given by

$$
h=\frac{N_{\mathrm{u}} \lambda}{D_{\mathrm{h}}} .
$$

Here $\lambda$ is thermal conductivity and the Nusselt number $N_{\mathrm{u}}$ is defined according to Forzatti correlation (Hayes and Kolaczkowski, 1997)

$$
N_{\mathrm{u}}=3.657+8.827\left(\frac{1000}{G_{\mathrm{z}}}\right)^{-0.545} \exp \left(-\frac{48.2}{G_{\mathrm{z}}}\right),
$$

where $G_{\mathrm{z}}$ is the Graetz number defined as a function of Reynolds number $R e$ and Prandtl number $P r$ according to

$$
G_{\mathrm{z}}=\frac{D_{\mathrm{h}}}{z} \operatorname{RePr}
$$

\subsection{Porous media flow}

Unlike the governing equations for channel flow, the species transport equations are written in the transient form. Species transport through porous bed is modeled in one dimension, but transverse to the direction of flow through the channel, given by

$$
\epsilon \frac{\partial\left(\rho Y_{k}\right)}{\partial t}+\frac{\partial\left(J_{k} W_{k}\right)}{\partial y}=A_{\mathrm{s}} \dot{s}_{k} W_{k}, \quad k=1, \ldots, K_{g},
$$

where $\epsilon$ is the porosity of the porous bed, $A_{s}$ is the specific catalyst area available for surface reaction and $\dot{s}_{k}$ is the heterogeneous production rate of the chemical species $k$. The species molar flux $J_{k}$ in the porous bed is evaluated according to

$$
J_{k}=-D_{\text {eff }} \nabla\left[X_{k}\right]-\frac{B_{\mathrm{g}}\left[X_{k}\right]}{\mu} \nabla p .
$$

The first term on the right hand side represents the flux due to concentration gradients and the second term on the right hand side represents the viscous flux. $\left[X_{k}\right]$ is the concentration of species $k$. The effective diffusion coefficient $D_{\text {eff }}$ is calculated according to

$$
\frac{1}{D_{\mathrm{eff}}}=\frac{1}{D_{\mathrm{km}}^{\mathrm{e}}}+\frac{1}{D_{k, \mathrm{Kn}}^{\mathrm{e}}} .
$$

The effective mixture diffusion coefficient $D_{\mathrm{km}}^{\mathrm{e}}$ is given by

$$
D_{\mathrm{km}}^{\mathrm{e}}=\frac{\varepsilon}{\tau} D_{\mathrm{km}},
$$

and the effective Knudsen diffusion coefficient is given by

$$
D_{k, \mathrm{Kn}}^{\mathrm{e}}=\frac{\varepsilon}{\tau} \frac{d_{\mathrm{p}}}{3} \sqrt{\frac{8 R T}{\pi W_{k}}} .
$$

In the above equations $\varepsilon$ is the porosity and $\tau$ is the tortuosity of the porous catalyst bed. $D_{\mathrm{km}}$ is the mixture diffusion coefficient 
for the species $k$ calculated according to:

$$
D_{\mathrm{km}}=\frac{\sum_{j \neq k}^{K_{g}} X_{j} W_{j}}{\bar{M} \sum_{j \neq k}^{K_{g}} X_{j} / D_{j k}} .
$$

Here, $\bar{M}$ is the average molecular weight of the mixture, $X_{j}$ is the mole fraction of species $j$, and $D_{j k}$ is binary diffusion coefficient calculated according to Chapman-Enskog theory. Assuming the catalyst bed is made up of spherical particles, the permeability $B_{\mathrm{g}}$ in Eq. 9 is given by Kozeny-Carman relationship

$$
B_{\mathrm{g}}=\frac{\varepsilon^{3} d_{\mathrm{p}}^{2}}{72 \tau(1-\varepsilon)^{2}},
$$

where $d_{\mathrm{p}}$ is the packed spherical particle diameter. The total density with the porous bed is evaluated from

$$
\epsilon \frac{\partial \rho}{\partial t}+\sum_{k=1}^{K_{g}} \frac{\partial\left(J_{k} W_{k}\right)}{\partial y}=\sum_{k=1}^{K_{g}} \dot{s}_{k} A_{\mathrm{s}} W_{k} .
$$

Once the density is known pressure $p$ is calculated from Eq. 3 .

\subsection{Plate energy balance}

In the following discussions, plate refers to the combined thickness of plate and the porous catalyst beds. Since the thickness of parallel plate reactor is much smaller compared to its length, any variation in temperature along the thickness is neglected and hence modeled in one dimension according to

$$
\rho_{\mathrm{s}} c_{\mathrm{p}} \frac{\partial T_{\mathrm{p}}}{\partial t}-\frac{\partial}{\partial z}\left(\lambda_{\mathrm{s}} \frac{\partial T_{\mathrm{p}}}{\partial z}\right)=Q
$$

The source term Q is calculated according to

$$
Q=-\frac{A_{\mathrm{c}}}{A_{\mathrm{p}}} \sum_{k=1}^{K_{g}} \frac{\mathrm{d}\left(\rho u h_{k} Y_{k}\right)}{\mathrm{d} z} .
$$

Here $A_{\mathrm{c}}$ and $A_{\mathrm{p}}$ are respectively the area of cross sections of the channel and plate. The enthalpy of the mixture changes due to change in composition and change in temperature. Therefore, this term represents change in enthalpy flux in the flow direction due to chemical reaction and heat exchange between plate and gas phase. A schematic of the same is shown in Fig. 2. Essentially we assume that all the heat due to chemical reactions is liberated with in the porous bed. The chemical heat source changes the temperature of the plate and the gas phase temperature changes due to heat exchange with the plate.

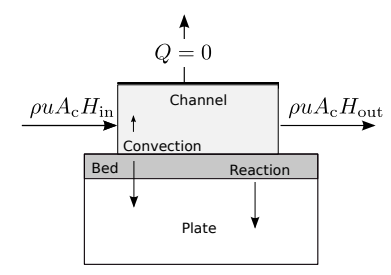

Figure 2: Schematic of heat exchange between solid and gas-channel

\subsection{Boundary conditions}

The inlet boundary conditions at time $t=0$ are given in Table 1. At the reactor exit the following Neumann boundary conditions are used for channel flow:

$$
\left.\frac{\mathrm{d} T}{\mathrm{~d} z}\right|_{z=L}=0,\left.\quad \frac{\mathrm{d} u}{\mathrm{~d} z}\right|_{z=L}=0,\left.\quad \frac{\mathrm{d} Y_{k}}{\mathrm{~d} z}\right|_{z=L}=0
$$

For the plate temperature Neumann boundary conditions are used at both ends. i.e.,

$$
\left.\frac{\mathrm{d} T_{\mathrm{p}}}{\mathrm{d} z}\right|_{z=0}=0,\left.\quad \frac{\mathrm{d} T_{\mathrm{p}}}{\mathrm{d} z}\right|_{z=L}=0
$$

At the interface between the dense plate and the porous bed zero flux boundary condition is imposed for species transport, i.e.

$$
J_{k}=0, \quad k=1, \ldots, K_{g} .
$$

\subsection{Solution algorithm}

The channel flow governing equations are solved by applying method of lines. However, the solution of these equations requires the flux $J_{k}$ at the interface and their evaluation needs the species composition within the porous media. For each axial position, time integration the porous media transport equations Eq. 8, 15 and 3 is performed until steady state to calculate the species mass fraction within the porous bed. This requires boundary conditions at $y=0$ and $y=H$. At $y=0$, i.e at the interface between the porous bed and solid plate Eq. 20 serves as the boundary condition. At $y=H$, i.e at the interface between the flow channel and the porous bed, the mass fractions in the gas-phase serve as the boundary condition. The reaction rates are evaluated at the plate temperature $T_{\mathrm{p}}$. The energy balance equation for the solid phase Eq. 16 is decoupled from the rest of the equation systems since the time scale of heat transport in the solid phase is larger compared to mass transport and chemical kinetics due to its larger heat capacity. i.e for each time step of solid-phase energy balance equation, one full marching of channel is performed from inlet to outlet. The whole program is implemented in $\mathrm{C}++$ and the set of governing equations are solved using the ordinary differential equation (ODE) solver CVODE (Hindmarch et al., 2005). Flow chart representing implementation of solution algorithm is shown in Fig. 3.

\subsection{Elementary kinetics}

We assume that the chemical reactions are occurring on the catalyst surface and any contribution by homogeneous gasphase reactions is neglected. The heterogeneous chemical reactions are implemented using detailed kinetic schemes. In this work we are considering $\mathrm{Rh}$ and $\mathrm{Ni}$ catalyst for reforming and Pt catalyst for combustion. The elementary step surface reaction mechanism for steam reforming of methane over $\mathrm{Rh}$ consists of 44 reactions among six gas-phase species and 12 surface adsorbed species (Schädel et al., 2009). Whereas the elementary step surface reaction mechanism for steam reforming of methane over $\mathrm{Ni}$ consists of 42 reactions among 


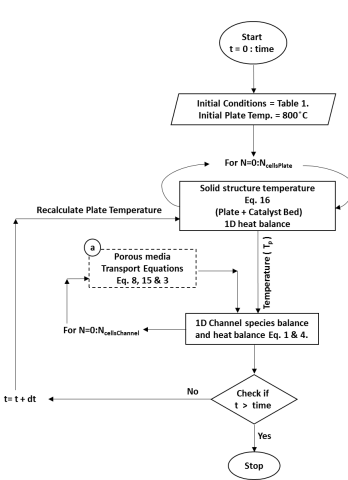

(a) Overall algorithm

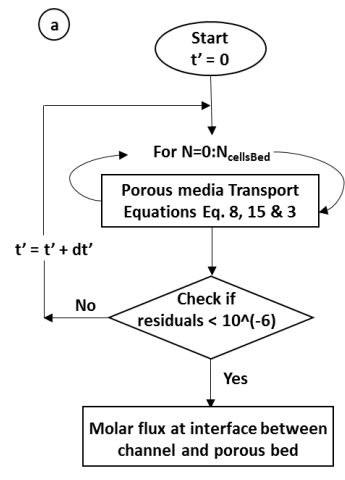

(b) Implementation of porous media solution
Figure 3: Flow chart showing the implementation of solution algorithm

six gas-phase species and 12 surface adsorbed species (Janardhanan and Deutschmann, 2006). The surface reaction mechanism used for the total oxidation of methane on Pt consists of 24 reactions among six gas-phase species and 10 surface adsorbed species (Deutschmann et al., 1996). The detailed implementation of kinetics is published elsewhere (Janardhanan and Deutschmann, 2011, Janardhanan et al., 2011, Appari et al., 2011)

\section{Results and discussion}

The inlet conditions and catalyst bed properties used for the simulations are given in Table 1. Since one of the easiest ways to manufacture CPR is by applying washcoat to plates, the properties of the catalyst bed are set close to that of washcoat structures commonly used in catalytic converters (Mladenov et al, 2010). Both $\mathrm{Rh}$ and $\mathrm{Ni}$ are used as reforming catalysts. However, higher $\mathrm{CH}_{4}$ conversions can be achieved by using $\mathrm{Rh}$ due to its higher catalytic activity compared to Ni. For the same active area Fig. 4 shows the conversions achieved by Rh catalyst as well as Ni catalyst as a function of reactor length for counter flow configuration. Flow is in the positive $z$ direction in the reforming channel and negative $z$ direction in the oxidation channel. Figure 4 also shows the plate temperature which is slightly lower for $\mathrm{Rh}$ compared to $\mathrm{Ni}$. The plate temperature peaks near the inlet of the oxidation channel, since the fuel ignites and temperature in the oxidation channel shoots up very close to the inlet. The temperature profiles within the reforming and oxidation channel respectively at different times as a function of reactor length are shown in Fig. 5 and Fig. 6. At time $t=0 \mathrm{~s}$, the plate is assumed to be uniform at $1073 \mathrm{~K}$ and the flow inlet temperature for the reforming and oxidation channel is set respectively at $523 \mathrm{~K}$ and $300 \mathrm{~K}$. Both fuel streams gain heat from the plate and the temperature rises within the initial few millimeters of their respective inlet. The temperature rise causes fuel ignition in the oxidation channel and hence the temperature peaks near the inlet. However, due to the counter flow arrangement, the oxidation channel looses and reforming channel gains temperature towards their

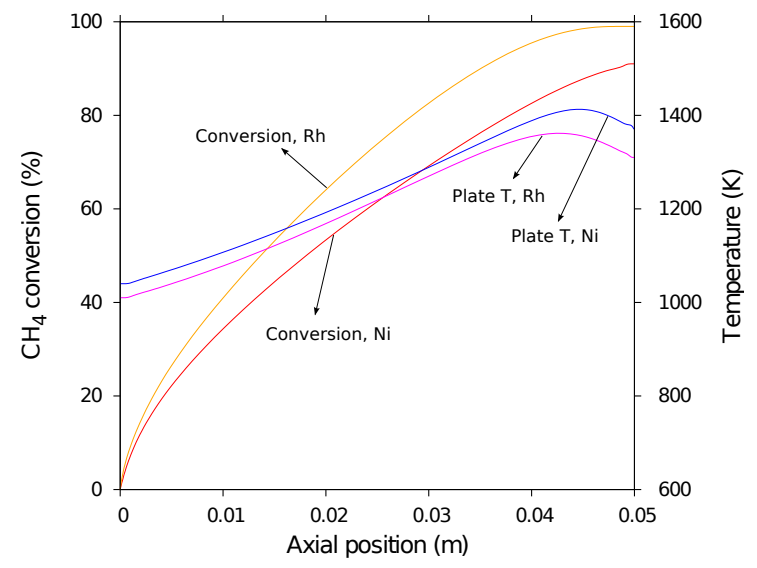

Figure 4: Temperature and $\mathrm{CH}_{4}$ conversion at steady state along the reactor for $\mathrm{Ni}$ and $\mathrm{Rh}$ catalyst. The inlet conditions and geometrical parameters are given in Table 1.

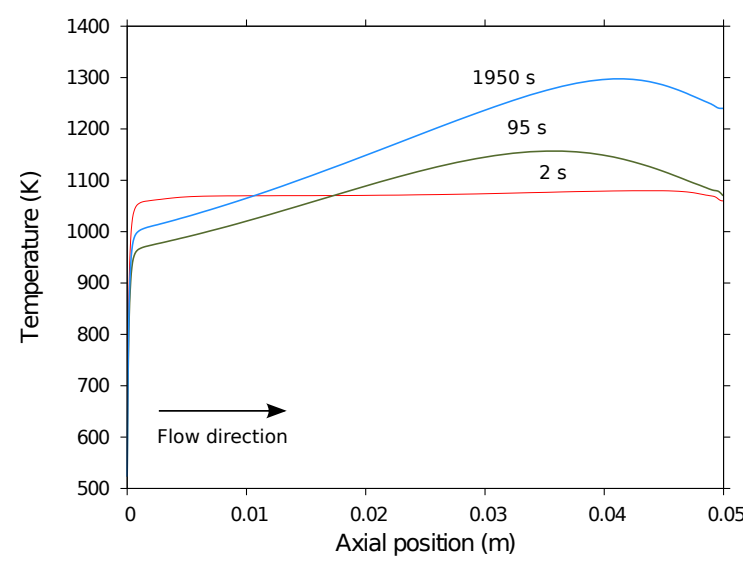

Figure 5: Temperature in the reforming channel along the reactor length at different times. The inlet conditions and geometrical parameters are given in Table 1.

respective reactor exits. The plate temperature is also highest near the oxidation channel inlet. Figure 7 shows the plate temperature at different times along the reactor length. Due to the higher catalytic activity of Rh, almost throughout the entire reactor length, $\mathrm{CH}_{4}$ conversions are higher for $\mathrm{Rh}$ compared to $\mathrm{Ni}$. With a $5 \mathrm{~cm}$ long reactor it is possible to achieve $100 \%$ conversion using Rh catalyst. However, for achieving $100 \%$ conversion using Ni catalyst one requires higher temperature. Venkataraman et al. (Venkataraman, 2003) reported the experimentally measured conversion and residence time in a three channel CPR arranged in co-flow configuration with $\mathrm{Rh}$ as reforming catalyst. For the same inlet conditions mentioned in the report, our numerical simulations predicted a residence time of $70 \mathrm{~ms}$ and $\mathrm{CH}_{4}$ conversion higher than $99 \%$ that matches very well the experimental measurements.

Numerical models can be extremely useful in designing the reactor. Figure 8 shows that higher conversions are possible by increasing the reactor length for fixed operating conditions. However, for the case considered here the increase in conversion is only $\sim 5 \%$, even though the length of reactor is doubled. 


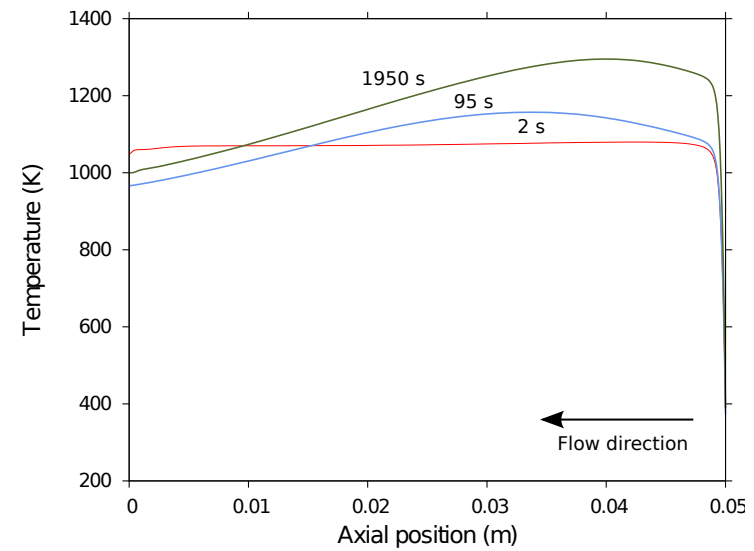

Figure 6: Temperature in the oxidation channel along the reactor length at different times. The inlet conditions and geometrical parameters are given in Table 1 .

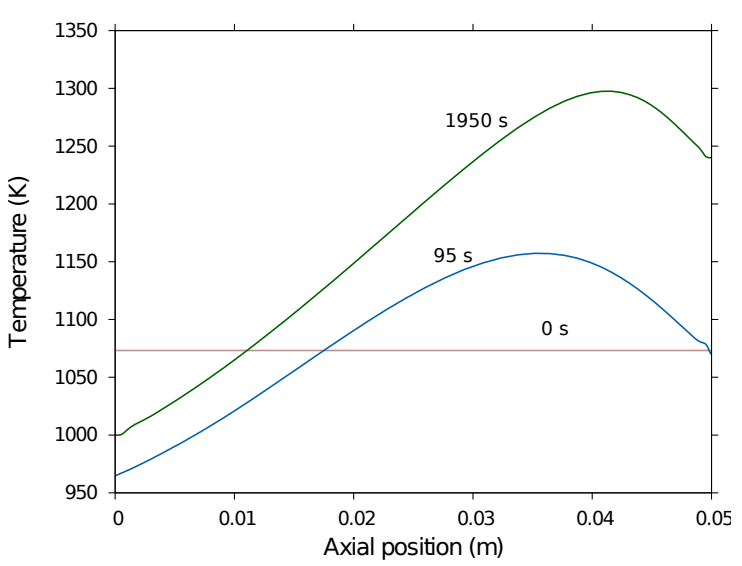

Figure 7: Temperature of the plate at different times as a function of CPR length. The inlet conditions and geometrical parameters are given in Table 1.

However, for a longer reactor, the maximum and minimum temperature of the plate is lower compared to shorter reactor. Since the conversions are not significantly different, one can assume that the enthalpy change in the flow channels of both reactors to be more or less the same. However, the longer reactor offers the possibility of better heat dissipation leading to overall lower temperatures. The inlet conditions used for these calculations are slightly different from what is given is Table 1. The inlet velocity at the reforming channel inlet is $0.2 \mathrm{~m} \mathrm{~s}^{-1}$ and the oxidation channel inlet velocity is $0.15 \mathrm{~m}$ $\mathrm{s}^{-1}$. The inlet composition and temperature to the reforming channel remains the same as given in Table 1 . However, the oxidation channel inlet compositions are $9.1 \% \mathrm{CH}_{4}$ and $91.9 \%$ Air at $300 \mathrm{~K}$.

The flow rates to the oxidation and reforming channels play a major role in deciding the conversion. For any given reforming channel flow rate, the plate temperature will increase as the oxidation channel flow rate increases due to higher molar fuel consumption. However, for ideal operation one should ensure that the resulting temperature does not exceed the material stability limits. Therefore, energy liberated in the oxidation

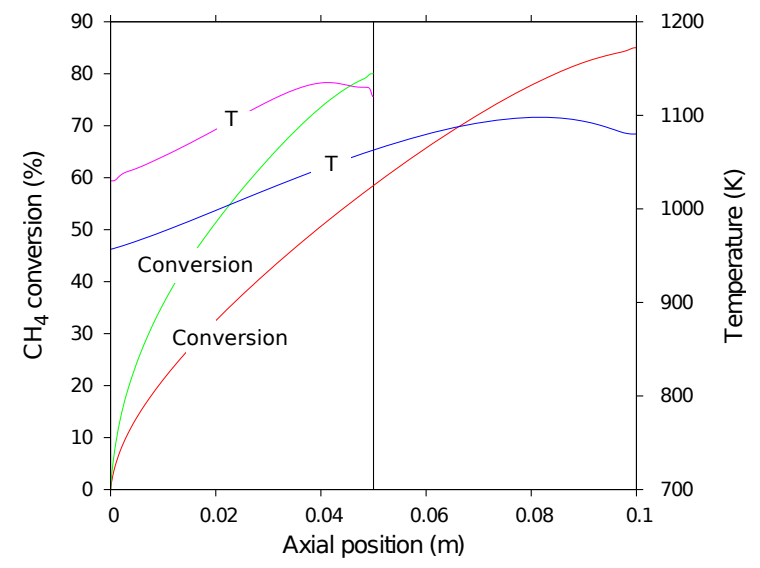

Figure 8: Effect of reactor length on $\mathrm{CH}_{4}$ conversion and plate temperature. Results are shown at steady state. Conditions are different for this one.

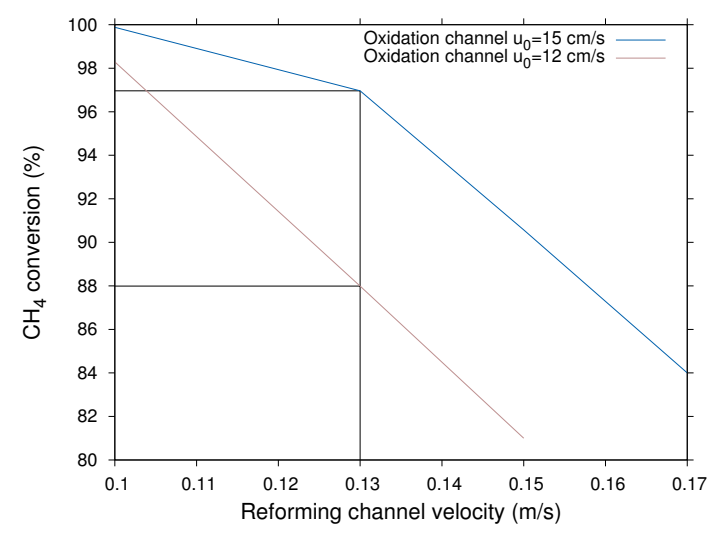

Figure 9: Effect of reforming side and oxidation side inlet velocity on $\mathrm{CH}_{4}$ conversion at steady state.

channel must ensure controlled plate temperature and desirable $\mathrm{CH}_{4}$ conversion in the reforming channel. Figure 9 shows that for a fixed reforming channel velocity the conversion increases by $\sim 10 \%$ as the oxidation channel inlet velocity increases by $0.03 \mathrm{~m} \mathrm{~s}^{-1}$. In other words for any given oxidation channel flow rate, higher conversions are possible by decreasing the reforming channel velocity. Nevertheless, when CPR is used for practical applications such as for high temperature fuel cells, it is not only the conversion but also the flow rate of synthesis gas matters.

Thermal conductivity/diffusivity of plate plays an important role as it serves to transfer heat from oxidation channel to reforming channel. Materials with high thermal conductivity will distribute heat throughout the plate at faster rate as compared to low conductivity materials. Ceramic materials like silica and fused silica have very low thermal conductivity i.e. from 1-5 $\mathrm{W} \mathrm{m}^{-1} \mathrm{~K}^{-1}$. These materials will develop hot spots that can severely affect catalyst performance and hence the whole system. According to our simulations with low conductivity material like fused silica, the plate temperature exceeds material stability limit (even though reforming side velocity was higher than oxidation channel velocity and maxi- 


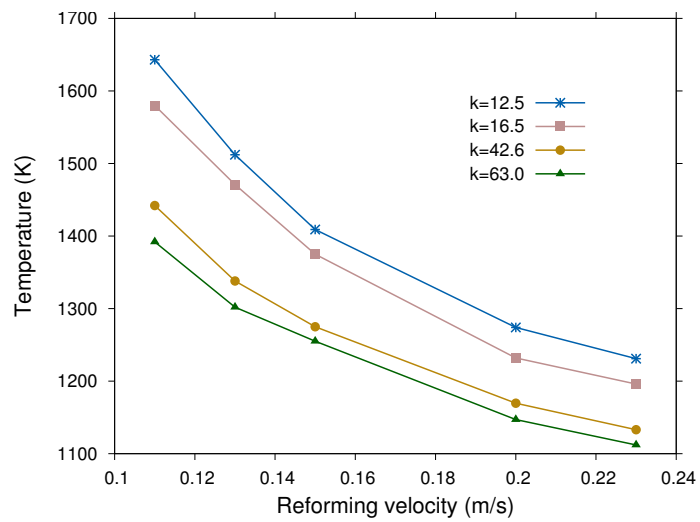

Figure 10: Effect of thermal conductivity $\left(\mathrm{W} \mathrm{m}^{-1} \mathrm{~K}^{-1}\right)$ of plate material on maximum plate temperature.

mum temperature achieved was $2500 \mathrm{~K}$ ). Figure 10 shows the maximum temperature in the plate as a function of reforming side velocity for different thermal conductivity (similar is the trend with thermal diffusivity, since $\rho \times c_{\mathrm{p}}$ considered is more or less the same for all cases). As expected the maximum temperature achieved decreases as the thermal conductivity increases.

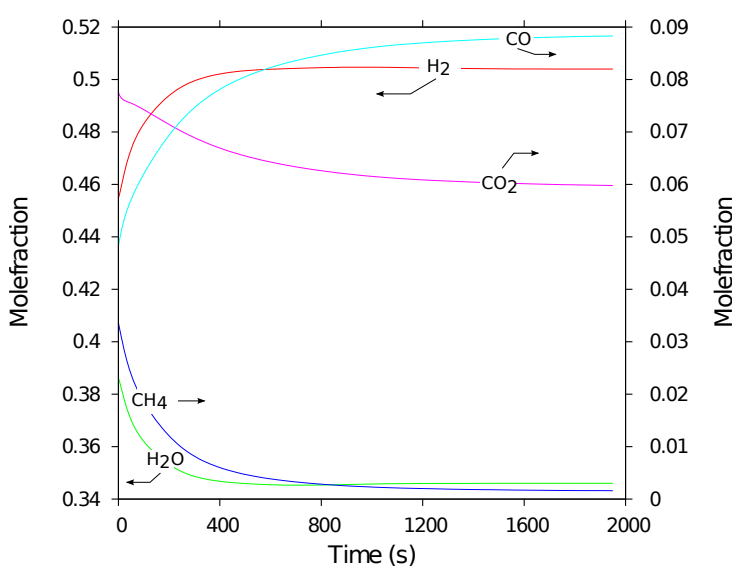

Figure 11: Exit mole fractions from reforming channel. The inlet conditions and geometrical parameters are given in Table 1.

Compositions at the reactor exit as a function of time are shown in Fig. 11. The major product from the reforming channel is $\mathrm{H}_{2}$. The $\mathrm{H}_{2}$ to $\mathrm{CO}$ ratio at the reactor exit at steady state is $\sim 5.7$. Although, traces of $\mathrm{CH}_{4}$ are present in the exit stream during the initial few second, as time progresses all $\mathrm{CH}_{4}$ gets consumed due to enhanced temperature as a result of heat transfer from the oxidation channel. The corresponding species profiles along the reactor length are displayed in Fig. 12. Close to $100 \%$ conversion of $\mathrm{CH}_{4}$ is achieved near towards the exit of the reforming channel.

Comparison between counter and co-flow arrangement is shown in Fig. 13 and Fig. 14. Figure 13 shows the plate temperature profile along the CPR at steady state for both the arrangements. Figure 14 shows that for the same conditions, counter flow configuration results in higher conversion

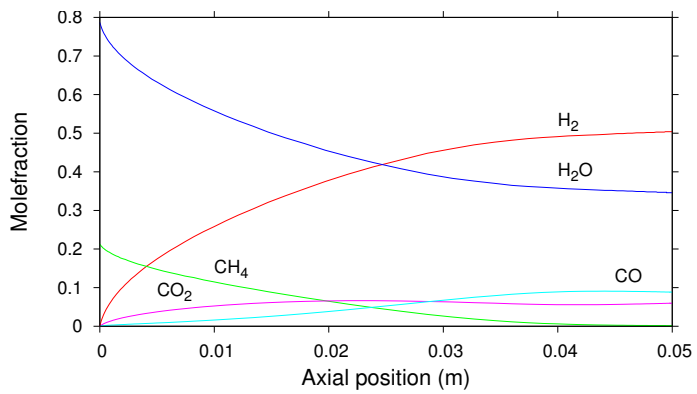

Figure 12: Species mole fraction along reactor length. Inlet conditions for reforming channel and oxidation channel are givem in Table 1

compared to co-flow arrangement. For co-flow arrangement the maximum attained plate temperature is $1180 \mathrm{~K}$ near the reactor inlet, where as for counter flow arrangement the maximum attained plate temperature is $1240 \mathrm{~K}$. Although, the initial conversions are higher for co flow arrangement, due to the higher plate temperature towards the exit, counter flow arrangement results in better conversions.

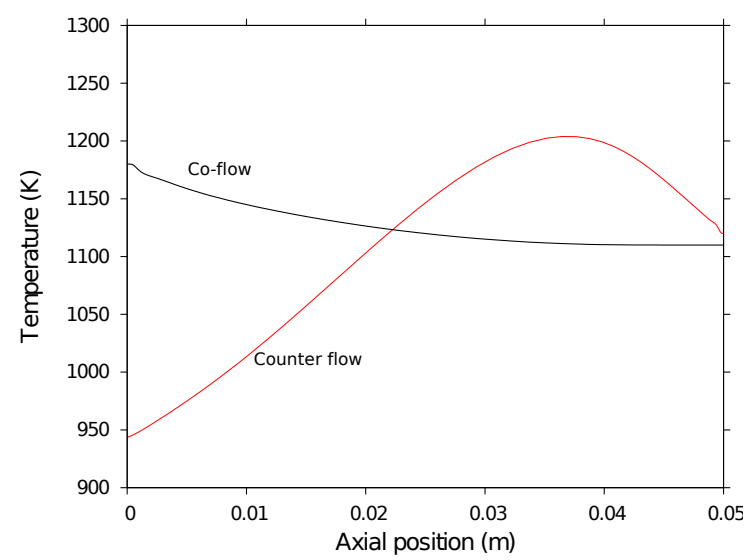

Figure 13: Comparison of temperature profile along the channels of CPR for co-flow and counter flow arrangement.

The number of CPRs required to produce the same capacity as that of an industrial steam reformer is given in Table 3. The calculations are performed based on industrial production data given in Table 2. The mole fractions from the industrial unit are very close to the values reported in this work. Assuming that 1000 CPRs are present in a stack arrangement, Table 3 gives the number of stacks required and the total volume the stacks would occupy. One certainly will have to account also for the pumping and piping requirement, that will increase the total volume requirement. Nevertheless, the calculations show that an industrial scale reformer can be replaced by a reformer technology based on CPR which will occupy far less foot print area.

\section{Conclusions}

Performance of co and counter flow CPR is studied for methane steam reforming coupled with methane oxidation us- 


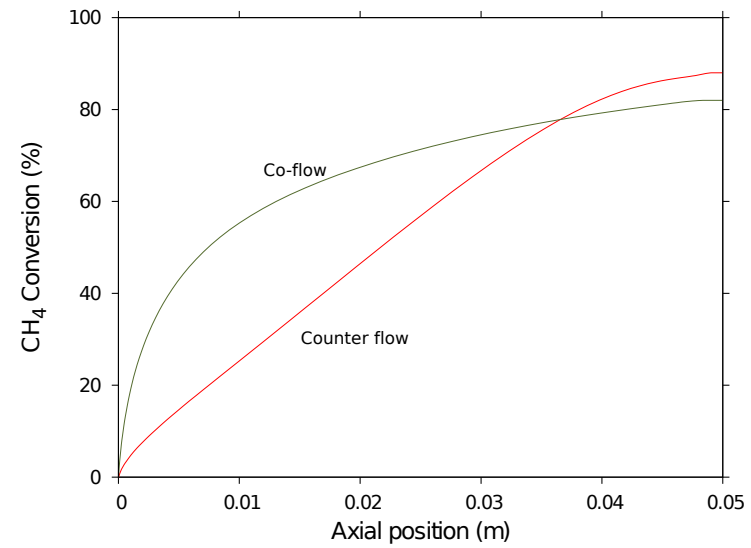

Figure 14: Comparison of conversion along the channels of CPR for co-flow and counter flow arrangement.

ing transient numerical scheme and detailed surface reaction mechanisms. More uniform plate temperature is obtained for co-flow arrangement and counter flow arrangement leads to higher temperature towards the reforming channel exit. Although, co-flow configuration leads to early conversion in the channel, final $\mathrm{CH}_{4}$ conversion is higher for counter flow configuration due to higher plate temperature towards the exit. Due to better heat dissipation longer reactors can lead to overall lower temperatures and hence can mitigate hot spot formation. Similarly high conductivity materials can also lead to more uniform plate temperatures. The composition of the reformer exit is very close to that of an industrial reformer and calculation reveal that an industrial scale reformer can be replaced with CPR units made up into stacks.

\section{References}

Appari, S., Janardhanan, V. M., Jayanti, S., Maier, L., Tischer, S., Deutschmann, O., 2011. Micro-kinetic modeling of NH 3 decomposition on $\mathrm{Ni}$ and its application to solid oxide fuel cells. Chem. Eng. Sci. 66 (21), 5184-5191.

Dean, L., 2008. Mathematical modeling of an industrial steam reformer. M S Thesis, Queens University, Ontario, Canada.

Deutschmann, O., Schmidt, R., Behrendt, F., Warnatz, J., 1996. Numerical modeling of catalytic ignition. In: Proceedings of the Combustion Institute. pp. 1747-1754.

Hayes, R. E., Kolaczkowski, S. T., 1997. Introcution to catalytic combustion. OPA, Amsterdam.

Hindmarsh, A. C., Brown, P. N., Grant, K. E., Lee, S. L., Serban, R., Shumaker, D. E., Woodward, C. S., 2005.SUNDIALS: Suite of nonlinear and differential/algebraic equation solvers. LLNL Technical Report, UCRL-JP-200037.

Janardhanan, V. M., Appari, S., Jayanti, S., Deutschmann, O., 2011. Numerical study of on-board fuel reforming in a catalytic plate reactor for solid-oxide fuel cells. Chem. Eng. Sci. 66 (3), 490-498.

Janardhanan, V. M., Deutschmann, O., 2006. CFD analysis of a solid oxide fuel cell with internal reforming: Coupled interactions of transport, heterogeneous catalysis and electrochemical processes. Journal of Power Sources 162 (2), 1192-1202.

Janardhanan, V. M., Deutschmann, O., 2011. Modeling diffusion limitation in solid-oxide fuel cells. Electrochimica Acta 56 (27), 9775-9782.

Kolb, G., Hessel, V., 2004. Micro-structured reactors for gas phase reactions. Chem. Eng. J. 98, 1-38.

Mladenov, N., Koop, J., Tischer, S., Deutschmann, O., 2010. Modeling of transport and chemistry in channel flows of automotive catalytic converters.

Polman, E. A., Kinderen, J. M., Thuis, F. M. A., 1999. Novel compact steam reformer for fuel cell with heat generation by catalytic combustion augmented by induction heating. Catal. Today 66, 347-351.

Schädel, B., Duisberg, M., Deutschmann, O., 2009. Steam reforming of methane, ethane, propane, butane, and natural gas over a rhodium-based catalyst. Catalysis Today 142, 42-52.

Stefanidis, G. D., Vlachos, D. G., Kaisare, N. S., Maestri, M., 2008. Millisecond methane steam reforming via process and catalyst intensification. Chem. Eng. Technol 31, 1201-1209.

Stefanidis, G. D., Vlachos, D. G., Kaisare, N. S., Maestri, M., 2009. Methane steam reforming at microscales: Operation strategies for variable power output at millisecond contact times. AIChE 55, 180-191.

Venkataraman, K., 2003. Short contact time catalytic plate reactor. Ph.d Thesis, University of Minnesota.

Zanfir, M., Gavriilidis, A., 2003. Catalytic combustion assisted methane steam reforming in catalytic plate reactor. Che. Eng. Sci. 58, 3947-3960.

Zanfir, M., Gavriilidis, A., 2004. Influence of flow arrangement in catalytic plate reactors for methane steam reforming. Chem. Eng. Res. Des. 82, 252 258.

Zhu, H., Kee, R. J., Janardhanan, V. M., Deutschmann, O., Goodwin, D. G., 2005. Modeling Elementary Heterogeneous Chemistry and Electrochemistry in Solid-Oxide Fuel Cells. J. Electrochem. Soc. 152 (12), A2427A2440. 


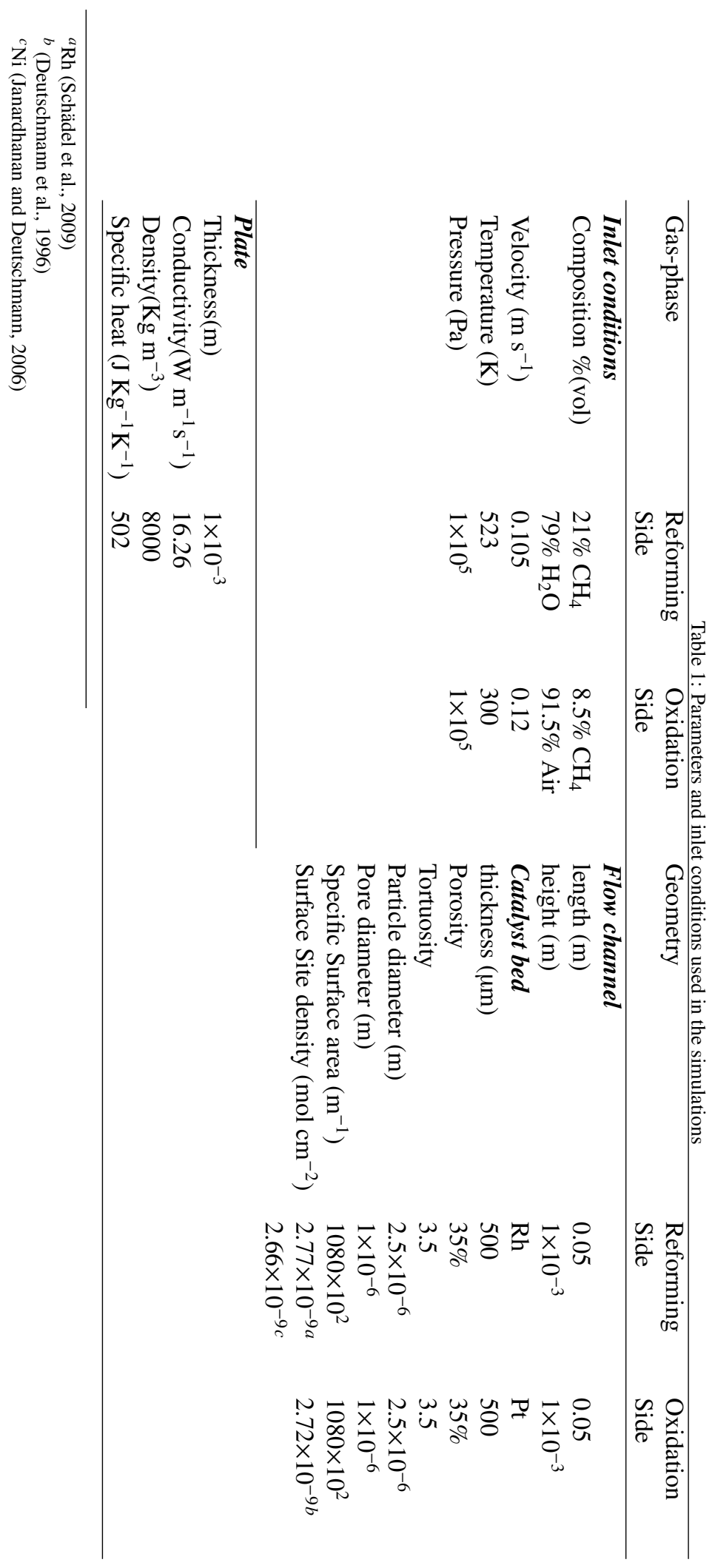


Table 2: Industrial steam reformer data form four different plants (Dean, 2008)

\begin{tabular}{|c|c|c|c|c|c|}
\hline Sybmol & Unit & Plant A & Plant B & Plant C & Plant D \\
\hline $\mathrm{T}_{\text {proc,out }}$ & ${ }^{\circ} \mathrm{C}$ & 832.4 & 834.0 & 848.9 & 835.8 \\
\hline $\mathrm{P}$ & $\mathrm{kPa}$ & 2846.1 & 2804.0 & 2879.8 & 2723.4 \\
\hline $\mathrm{n}_{\text {proc,out }}$ & gmol/h & $1.085 \times 10^{7}$ & $9.776 \times 10^{6}$ & $1.001 \times 10^{7}$ & $7.422 \times 10^{6}$ \\
\hline $\mathrm{XH}_{2}$ & - & 0.458 & 0.463 & 0.471 & 0.465 \\
\hline $\mathrm{XCO}$ & - & 0.082 & 0.084 & 0.088 & 0.085 \\
\hline $\mathrm{XCH}_{4}$ & - & 0.05 & 0.053 & 0.045 & 0.048 \\
\hline $\mathrm{XCO}_{2}$ & - & 0.058 & 0.057 & 0.055 & 0.057 \\
\hline $\mathrm{XH}_{2} \mathrm{O}$ & - & 0.351 & 0.342 & 0.337 & 0.343 \\
\hline
\end{tabular}

Table 3: Number of CPR and stacks required for industrial production capacity reported in Table 2

\begin{tabular}{|l|c|c|c|c|}
\hline & Plant A & Plant B & Plant C & Plant D \\
\hline $\begin{array}{l}\text { Product Rate } \\
(\mathrm{gmol} / \mathrm{h})\end{array}$ & $1.085 \times 10^{7}$ & $9.776 \times 10^{6}$ & $1.001 \times 10^{7}$ & $7.422 \times 10^{6}$ \\
\hline $\begin{array}{l}\text { Number of CPR re- } \\
\text { quired }\end{array}$ & 1115485 & 1005067 & 1029125 & 763053 \\
\hline Number of stacks ${ }^{a}$ & 1116 & 1005 & 1029 & 763 \\
\hline $\begin{array}{l}\text { Total stack Volume } \\
\text { Required }\left(\mathrm{m}^{3}\right)\end{array}$ & 0.1942 & 0.1756 & 0.1814 & 0.1335 \\
\hline
\end{tabular}

${ }^{a}$ Each stack contains 1000 CPRs 